\title{
PILOMATRIXOMA OF FACE PRESENTING AS PAROTID SWELLING
}

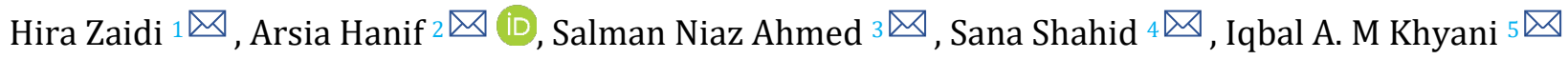 \\ 1,3,5 Department of Otolaryngology, Dow University Hospital, Karachi, Pakistan \\ 2 Dow University of Health and Sciences, Karachi, Pakistan \\ ${ }^{4}$ Department of Surgery, Civil Hospital Karachi, Pakistan
}

Received 18 October 2021

Accepted 3 November 2021

Published 30 November 2021

\section{CorrespondingAuthor}

Hira Zaidi, hirazaidi144@gmail.com

DOI

10.29121/granthaalayah.v9.i11.2021 .4391

Funding: This research received no specific grant from any funding agency in the public, commercial, or not-for-profit sectors.

Copyright: (C) 2021 The Author(s). This is an open access article distributed under the terms of the Creative Commons Attribution License, which permits unrestricted use, distribution, and reproduction in any medium, provided the original author and source are credited.

\section{ABSTRACT}

Pilomatrixoma, also known as pilomatrixoma or calcifying epithelioma of Malherbe, is a benign tumor of skin appendages. Although it is an uncommon and benign neoplasm of the head and neck region, it may sometimes become malignant. It arises from the cells of the outer sheath of the hair follicle root. Owing to its rarity, pilomatrixoma can be missed during differential diagnosis, and it can be misdiagnosed as malignancy. Therefore, for definitive and confirmatory diagnosis, histopathological analysis is imperative. We report a case of a 26-year-old female who presented with hard swelling on the right side of her face near the angle of the mandible. We have discussed its clinical, radiological, and histological findings and reflected light on the treatment of choice for pilomatrixoma.

Keywords: Pilomatrixoma, Benign Neoplasm, Skin Adnexa, Preauricular Region

\section{INTRODUCTION}

Pilomatrixoma, also called calcifying epithelioma of Malherbe, was first described by Malherbe and Chenantais in 1880. It arises from the sebaceous glands as a benign calcified neoplasm of hair follicles' matrix cells Sannigrahi et al. (2016). In 1922, Dubreuilh and Cazenave described the distinctive histopathology of basaloid cells and shadow or ghost cells Kashif and Shastry (2016). Forbis and Helwig, in 1961, suggested its name to eradicate any confusion with malignancy. Moreover, the suggested name, pilomatrixoma, is a self-explanatory name attributable to its origin from the hair matrix cells Pant et al. (2010). Affected individuals are usually asymptomatic besides having a solitary, slow-growing, mobile, and subcutaneous or intradermal firm nodule Nadershah et al. (2012). A vast majority of the affected individuals are Caucasians. Pilomatrixoma often presents in the first two decades of life and has a slight female predominance with a female to male ratio of 3:2. In general, the tumor typically has a good prognosis Sannigrahi et al. (2016).

\section{CASE PRESENTATION}

A 20-year-old female presented to the outpatient department of otolaryngology with a history of progressively enlarging swelling on the right side of the face for the past 5 months. The swelling was initially small and developed near the angle of the mandible. However, over the next few months till the presentation, the swelling had increased in size. The patient denied any other swelling, pain, tenderness, trauma, fever, chills, fatigue, or weight loss. On physical examination, 
inspection revealed a hard, smooth- surfaced, oval-shaped, and well-defined swelling measuring $3 \times 3 \mathrm{~cm}$ in diameter. The overlying skin was normal in color, and so was the surrounding skin. No redness, warmth, or discharge was noticed. On palpation, it was stony hard, non-tender, non-fluctuant, mobile in all directions, and not adherent to the overlying skin or underlying structures. The lesion was noncompressible, irreducible, non-pulsatile, and non-translucent. Cervical lymph nodes were not palpable. Examinations of the facial muscles and oral cavity were unremarkable. No axillary or femoral adenopathy was noticed. The rest of the examination was unremarkable and did not reveal any swelling in any other part of the body.

Ultrasonography revealed a well-defined, heterogeneous area measuring $2.6 \times 1.3 \mathrm{~cm}$. It was seen subcutaneously in front of the right submandibular angle. No vascularity was appreciated on color doppler imaging, and the right parotid gland appeared normal. Fine needle aspiration cytology identified a few scattered lymphocytes along with neutrophils and histiocytes against a hemorrhagic background. No malignant cells were noticed.

With the patient's consent, she was prepared for excisional biopsy of the mass under general anesthesia. A small vertical incision was given on the skin, and the mass was successfully excised. The specimen was sent for histopathological evaluation, which revealed a circumscribed lesion containing squamous and basal layers and basaloid cells in the dermis. The cells had round to oval, hyperchromatic nuclei, and scanty cytoplasm. Some clusters of eosinophilic cytoplasm were also observed.

Moreover, ghost squamous cells were also noted. Biopsy revealed keratinous material with foci of calcifications. The epidermis was unremarkable, and there was no evidence of malignancy. In brief, the histopathological features confirmed the diagnosis of pilomatrixoma.

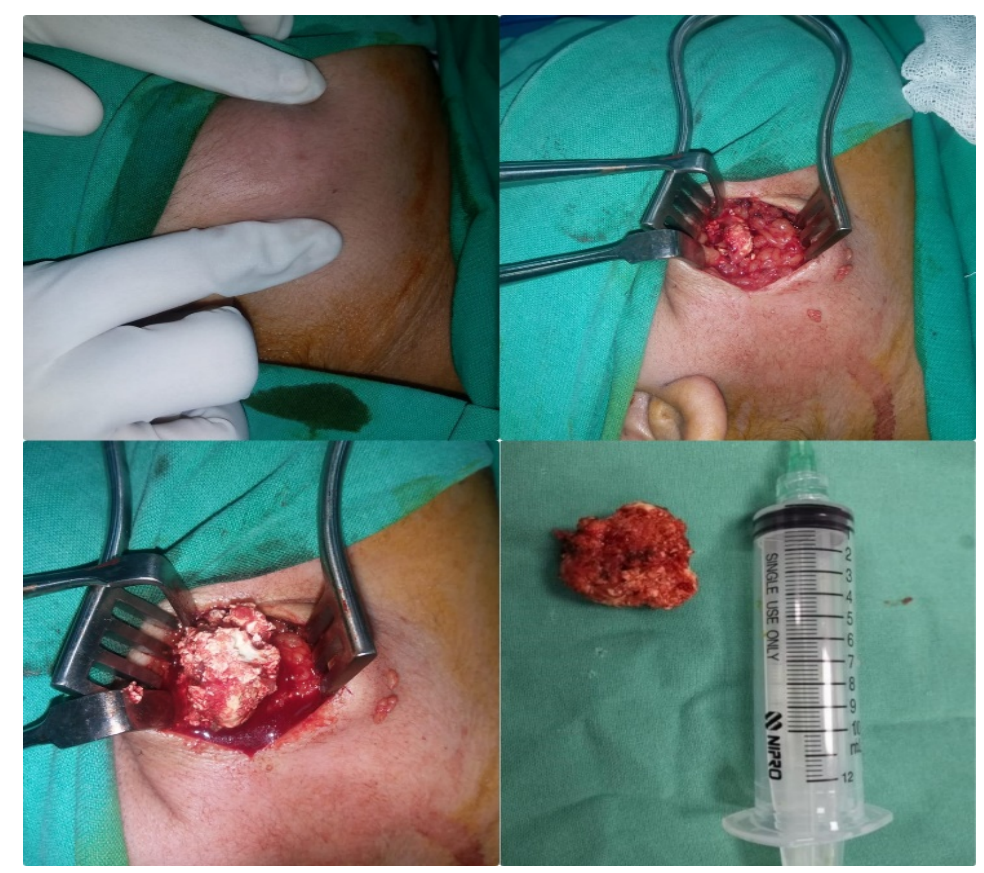

Figure 1 Gross appearance of irregular and nodular tumor measuring about 4x2cm in dimension. 


\section{DISCUSSION}

Pilomatrixoma is a rare benign neoplasm of skin adnexa originating from the matrix cells of hair follicles. Approximately 50 percent of the reported pilomatrixoma cases involve the head and neck region, with the preauricular region being the most consistent location Nadershah et al. (2012). However, there have been cases in the literature with pilomatrixoma in various upper extremity locations too. The typical presentation is of an asymptomatic, solitary, painless, mobile, firm, subcutaneous or intradermal nodule measuring less than $3 \mathrm{~cm}$. However, giant pilomatrixoma can be more than $5 \mathrm{~cm}$ in diameter. The lesions are oval with welldemarcated margins. Some encapsulated Sannigrahi et al. (2016) lesions have also been observed. Moreover, the overlying skin is usually normal, but in some cases, a reddish-bluish hue can be seen due to angiogenesis Birman et al. (2009). "Tent sign" is the pathognomic sign of pilomatrixoma demonstrated by stretching the skin over the tumor, which causes flattening of the tumor's surface with multiple facets and angles Kashif and Shastry (2016), Nadershah et al. (2012), Birman et al. (2009). Also, pressing on one edge of the lesion protrudes the lesion from the other side like a "teeter-totter." Both of these signs are typical of pilomatrixoma, thus the most helpful clues for diagnosis Kashif and Shastry (2016). The differential diagnoses of pilomatrixoma include epidermoid cyst, sebaceous cysts, dermoid cysts, hematoma, trichoepithelioma, basal cell epithelioma, unidentified masses, and foreign bodies reactions Sannigrahi et al. (2016), Birman et al. (2009). Often the lesions of pilomatrixoma are misdiagnosed as one of the differentials. Also, it is imperative to rule out other diseases in patients presenting with pilomatrixoma as it is associated with granulomatous diseases such as sarcoidosis, genetic disorders, including Turner syndrome, Gardner syndrome, Xeroderma pigmentosa, basal cell nevus syndrome, and Steinert myotonic dystrophy Sannigrahi et al. (2016) , Birman et al. (2009).

Radiography is generally non-diagnostic as pilomatrixoma is a small, superficial, and well-circumscribed lesion. Plain radiography shows nonspecific calcifications of the lesion. Ultrasonography characteristically shows an ovoid, complex mass at the junction of the dermis and subcutaneous fat with focal thinning of the overlying dermis. Moreover, the lesion appears similar to a target lesion with a hypoechoic rim and an echogenic center. Ultrasonography may also show calcifications Hugheset al. (1999).

In a study, 4 out of 33 patients underwent computed tomography scans of the parotid region. The CT scan showed a well-demarcated, subcutaneous tumor with microcalcifications and metabolic activity, which the radiologist diagnosed as adenopathy Duflo et al. (1998). MRI may be diagnostic if further reports confirm the correlation between the high signal bands in T2-weighted images and the bands formed by basaloid cells evident upon histological examination Ichikawa et al. (1997). Fine-needle aspiration has been studied as a diagnostic tool; however, misinterpretation of the lesion as carcinoma, basal cell carcinoma, and pleomorphic adenoma with squamous metaplasia has been reported. The presence of ghost cells, basaloid cells, and calcium deposits in the appropriate clinical setting permits diagnosis by aspiration Birman et al. (2009).

Histopathological features of pilomatrixoma are usually found in the lower dermis and subcutaneous fat. It is a well-circumscribed tumor surrounded by a connective tissue capsule. It consists of either basophilic cells or shadow cells which are islands of epithelial cells. Although these ghost cells are not a pathognomic feature of pilomatrixoma, they are quite specific to pilomatrixoma. These ghost cells 
are more evident in mature tumors. When the tumor matures, gradually, a central degeneration is seen in the basaloid cells. This casts an anucleated central shadow forming ghost cells or shadow cells. In other words, as the tumor matures, the number of ghost or shadow cells increases, whereas basaloid cells decrease in number.

Some of the other characteristic features include inflammatory reaction, giant cells, central calcifications, and keratin debris. In $75 \%$ of the tumors, calcium deposits are found using Von Kossa stain Kashif and Shastry (2016), Birman et al. (2009), Kaddu et al. (1996).

Pilomatrix carcinoma is a rare malignant counterpart of pilomatrixoma, with approximately 90 reported cases in the literature. It is a locally aggressive tumor with a higher risk of recurrence. Although the majority are locally aggressive, several cases have demonstrated distant metastases too. Many of the key features are similar between the two, i.e., pilomatrixoma and pilomatrix carcinoma. However, the latter's primary differentiating characteristics include a high mitotic rate with atypical mitoses, central necrosis, infiltration of the skin and soft tissue, and invasion of blood and lymphatic vessels Kashif and Shastry (2016), Birman et al. (2009).

Pilomatrixoma never regresses spontaneously. Therefore, the treatment of choice is surgical excision Morales and McGoey (1980), Thomas et al. (1999). Intraoperatively, it is imperative to save the facial nerve branches without compromising adequate tumor excision because inadequate excision increases the risk of local recurrences. Therefore, to minimize the recurrence risk, wide resection of margins, i.e., 1 to $2 \mathrm{~cm}$, is recommended Nadershah et al. (2012), Jones et al. (2018). With complete excision, it has a low recurrence rate, ranging from 0 to $3 \%$ Kashif and Shastry (2016), Nadershah et al. (2012), Birman et al. (2009). Postoperatively, it is crucial to conduct a thorough dermatological evaluation and advise a long-term follow-up to ensure the lesion does not recur Sannigrahi et al. (2016), Jones et al. (2018). For patients with numerous pilomatrixoma, all lesions should be excised. Moreover, ruling out associated or familial conditions remains indispensable Jones et al. (2018).

\section{CONCLUSION}

Pilomatrixoma is a benign neoplasm that usually presents as a single, slowgrowing, subcutaneous or intradermal nodule. It usually measures less than $3 \mathrm{~cm}$ and commonly affects the face. Malignant transformation has been reported but it is very rare. The diagnosis is established based on an incisional biopsy with questionable value of FNAC. The treatment of choice is surgical excision with a clear margin with every effort to preserve the branches of the facial nerve. After surgical excision, long term follows up and regular dermatological evaluation is mandatory to monitor for recurrence. However, recurrence with adequate treatment is low.

\section{AUTHORS' CONTRIBUTIONS}

All authors made equal contributions and all authors read and approved the final manuscript.

\section{PATIENT'S CONSENT}

Verbal and written consent was taken from the patient for publication. 


\section{ACKNOWLEDGMENTS}

The authors would like to acknowledge the Ojha Institute of Chest Diseases of Dow University of Health Sciences for facilitating the study.

\section{REFERENCES}

Birman MV, McHugh JB, Hayden RJ, Jebson PJ. (2009) "Pilomatrixoma of the forearm." Iowa Orthop J. ;29:121-123. Retrieved from https://www.ncbi.nlm.nih.gov/pmc/articles/PMC2723706

Duflo S, Nicolas R, Roman S, Magalon G, Triglia JM. (1998) "Pilomatrixoma of head and neck in children." Arch Otolaryngol Head Neck Surg.;124(11). Retrieved from https://doi.org/10.1001/archotol.124.11.1239

Hughes J, Lam A,Rogers M. (1999) "Use of ultrasonography in the diagnosis of childhood pilomatrixoma." Pediatr Dermatol.;16(5):341-4. Retrieved from https://doi.org/10.1046/j.1525-1470.1999.00090.x

Ichikawa T,Nakajima Y, Fujimoto H, etal. (1997) "Giant calcifying epithelioma of Malherbe (pilomatrixoma)." Skeletal Radiol.; 26(10):602-5. Retrieved from https://doi.org/10.1007/s002560050293

Jones CD, Ho W, Robertson BF, Gunn E, Morley S. (2018) "Pilomatrixoma:A Comprehensive review of the literature." Am J Dermatopathol.;40(9):63141. Retrieved from https://doi.org/10.1097/DAD.0000000000001118

Kaddu S, Soyer HP, Hodl S, kerl H. (1996) "Morphological stages of pilomatricoma."Am J Dermatopathol; 18(4):333-8. Retrieved from https://doi.org/10.1097/00000372-199608000-00001

Kashif MM, Shastry S. (2016) "Pilomatrixoma of right scapular region". Med J DY Patil Vidyapeeth.: 9(3);370-3. Retrieved from https://doi.org/10.4103/0975-2870.182510

Morales A, McGoey J. (1980) "Pilomatricoma treatment by incision and curettement".J Am Acad Dermatol. ;2(1)44-6. Retrieved from https://doi.org/10.1016/S0190-9622(80)80291-X

Nadershah M, Alshadwi A, Salama A. (2012) Recurrent giant pilomatrixoma of the face: a case report and review of the literature. Case Rep Dent.;2012:197273. Retrieved from https://doi.org/10.1155/2012/197273

Pant I, Joshi SC, Kaul G, Kumar G. (2010) "Pilomatricoma as a diagnostic pit fall in clinical practice." Indian J. Dermatol.;55:390-2. Retrieved from https://doi.org/10.4103/0019-5154.74566

Sannigrahi R, Saha J,Ghosh D,Biswas SK, Basu SK. (2016) "Pilomatrixoma-A Case Reoprt" Otolaryngol (Sunnyvale);;6(4):251. Retrieved from https://doi.org/10.4172/2161-119X.1000251

Thomas RW, Perkins JA,Ruegemer JL. (1999) "Munaretto JA. Sugical excision of pilomatrixoma of the head and neck." Ear Nose Throat J. ;78(8):541,5446,548. Retrieved from https://doi.org/10.1177/014556139907800807 